\title{
EFFECT OF TEMPERATURE ON CORROSION INHIBITION OF COPPER - NICKEL ALLOY BY TETRAETHYLENEPENTAMINE UNDER FLOW CONDITIONS
}

\author{
ANEES A. KHADOM \\ Department of Chemical Engineering, College of Engineering, Daiyla University, Baquba 32001, Daiyla governorate, Iraq.
}

\section{ABSTRACT}

The corrosion of copper - nickel alloy in hydrochloric acid was investigated at different temperatures, inhibitor concentrations, and corrosive solution rotation rates. Weight loss technique was used to evaluate the corrosion rate data. Tetraethylenepentamine was used as organic corrosion inhibitor, while hydrochloric acid was the corrosive solution. Different parameters, such as inhibitor efficiency, activation energy were obtained. Corrosion rate increased with both temperature and acid rotation rate, while it decreased with increases of Tetraethylenepentamine concentration. Maximum inhibitor efficiency was at lower level of temperature, acid rotation rate and higher level of inhibitor concentration.

Keywords: Corrosion inhibition; hydrochloric acid; kinetic parameters; fluid flow.

\section{INTRODUCTION}

Copper alloys are widely used metal with an extensive industrial application. The study of its corrosion inhibition is a subject of great importance which has attracted much attention. In fact, the corrosion of metallic materials in acidic solution causes considerable costs [1]. One of the most practical methods for protection against corrosion in acidic media is use of inhibitors [2-16]. Most of the efficient organic inhibitors are the compounds which contain hetero-atoms such as oxygen, nitrogen, sulfur, and phosphorus which allowed adsorption on the metal surface [17]Various corrosion inhibitors were suggested for copper inhibition in acidic solutions, but not all of them can be used for a long time $[18,19]$. However, it remains an important objective that one can either find a new inhibitor or to improve the efficiency of a known inhibitor by applying a synergistic technique [20]. Many organics compounds are widely used as inhibitors in various industries. The organic molecules adsorb on the metal surface through heteroatom, such as nitrogen, oxygen, and sulfur, blocking the active sites and generating a physical barrier to reduce the transport of corrosive species to the metal surface [21,22]. The amines are an interesting group of nitrogen containing organic compounds, which act as inhibitors in the dissolution of metals in aggressive media by adsorbing at the metal-solution interface. They have been studied as corrosion inhibitors for various metals in several media $[23,24]$. The inhibiting action of these inhibitor compounds is usually attributed to their interactions with the copper surface via their adsorption. Polar functional groups are regarded as the reaction center that stabilizes the adsorption process. However, the adsorption of an inhibitor on a metal surface depends on the nature and the surface charge of the metal, the adsorption mode, its chemical structure, and the type of the electrolyte solution [25 - 27]. The aim of present paper was to study the effect of temperature and rotation rate on the corrosion of copper - nickel alloy in hydrochloric acid in presence of Tetraethylenepentamine as a corrosion inhibitor.

\section{EXPERIMENTAL WORK}

The corrosion behavior of copper-nickel alloys, which used widely in many industrial equipments, was studied using weight loss in absence and presence Tetraethylenepentamine (TEPA) in $5 \% \mathrm{HCl}$ solution at different temperature $\left(25,35,45\right.$, and $\left.55{ }^{\circ} \mathrm{C}\right)$, different velocities $(100,200$, and $300 \mathrm{rpm})$, and different inhibitor concentrations $(0.05$ and $0.005 \mathrm{M})$. Ring shape specimen of $\mathrm{Cu}-\mathrm{Ni}$ alloy with dimension $(2.22 \mathrm{~cm})$ outside diameter, $(1.5 \mathrm{~cm})$ width, and $(0.13 \mathrm{~cm})$ thickness, exposing a surface area of about $\left(10 \mathrm{~cm}^{2}\right)$ to corrosive media. Specimens were washed by detergent and flushed by tap water followed by distilled water, degreased by analar benzene and acetone, then annealed in vacuums to $600{ }^{\circ} \mathrm{C}$ for one hour and cooled under vacuum to room temperature. Before each run, specimens of $\mathrm{Cu}-\mathrm{Ni}$ were abraded in sequence using emery paper of grade number $220,320,400$, and 600 , then washed by running tap water followed by distilled water then dried by clean tissue, degreased with benzene, dried, degreased with acetone, dried, and finally left in desicater over silica gel. Weighing the specimen was carried out using 4 decimals digital balance and its dimensions were measured with vernier. The metal samples for weight loss runs were completely immersed in $250-\mathrm{cm}^{3}$ solution of corrodant contained in a conical flask. They were exposed for a period of three days at a desired temperature, acid concentration, and inhibitor concentration. Weight losses were determined in absence and presence of inhibitors. Each test was carried out in duplicate and the average value was taken. The data are expressed as mass loss per unit time per unit area; in the present work the units of corrosion rate were $\mathrm{g} / \mathrm{m}^{2}$.day (gmd). The chemical compositions of $\mathrm{Cu}-\mathrm{Ni}$ alloy were $(0.148 \% \mathrm{Sn}, 0.2 \% \mathrm{Fe}, 0.134 \% \mathrm{Zn}, 0.015 \% \mathrm{Al}, 0.0003 \% \mathrm{P}, 0.5 \% \mathrm{Sb}, 0.0583 \% \mathrm{~Pb}$, $0.0202 \% \mathrm{Si}, 0.017 \% \mathrm{~S}, 0.0056 \% \mathrm{As}, 10 \% \mathrm{Ni}$, and the balance is $\mathrm{Cu}$ ).

\section{RESULTS AND DISCUSSIONS}

Table 1 shows the corrosion rate data of $\mathrm{Cu}-\mathrm{Ni}$ alloy obtained at different temperature and acid velocities in absence and presence of 0.005 and $0.05 \mathrm{M}$ TEPA as a corrosion inhibitor. Corrosion rates were obtained by the following equation [17]:

$$
C R=\frac{\text { weight loss }(g)}{\text { Area }\left(m^{2}\right) \times \text { Time }(\text { day })}
$$

From the corrosion rate, the percentage inhibition efficiency was calculated using the following equation:

$$
I E \%=\frac{C R_{\text {uninibit }}-C R_{\text {tnhibit }}}{C R_{\text {uninhibit }}} \times 100
$$

where $\mathrm{CR}_{\text {uninhibit }}$ and $\mathrm{CR}_{\text {inhibit }}$ are the corrosion rates in the absence and presence of inhibitor respectively. It is clear from Table 1 that the corrosion rate increased with both temperature and acid rotation rate, while it decreased with inhibitor concentration. Maximum inhibitor efficiency was $88.87 \%$ at $0.05 \mathrm{M}$ inhibitor efficiency, $100 \mathrm{rpm}$ rotation rate and $25{ }^{\circ} \mathrm{C}$. While the minimum value was $32.5 \%$ at $0.005 \mathrm{M}$ inhibitor efficiency, $300 \mathrm{rpm}$ acid rotation rate and $55^{\circ} \mathrm{C}$.

1.1 Effect of temperature and activation energy

Temperature has a great effect on the rate of metal electrochemical corrosion. In case of corrosion in a neutral solution (oxygen depolarization) the increase in temperature has a favorable effect on the overpotential of oxygen depolarization and the rate of oxygen diffusion but it leads to a decrease of oxygen solubility. In case of corrosion in an acidic medium (hydrogen depolarization), the corrosion rate increases exponentially with temperature increase because the hydrogen evolution overpotential decreases [17]. The effect of temperature and Activation parameters for some systems can be estimated from an Arrhenius-type plot equation [18]. 


$$
C R=A \operatorname{Exp}\left(-\frac{E}{R T}\right)
$$

Where, $\mathrm{CR}$ is corrosion rate, A is modified frequency factor (preexponential factor), E is activation energy $(\mathrm{J} / \mathrm{mole}), \mathrm{R}$ is gas constant $(8.314 \mathrm{~J} / \mathrm{mole} . \mathrm{K})$, and $\mathrm{T}$ is absolute temperature $(\mathrm{K})$. Equation 3 was written in linear form as:

$$
\ln C R=\ln A-\frac{E}{R T}
$$

The plot of $\ln C R$ versus reciprocal of absolute temperature, $1 / T$, gives a straight line with slope equal to $-\mathrm{E} / \mathrm{R}$, from which the activation energy for the corrosion process can be calculated. The Arrhenius plots for the corrosion of $\mathrm{Cu}-\mathrm{Ni}$ alloy in the hydrochloric acid containing inhibitor are shown in Fig. 1. The chemically stable surface active inhibitors increase the energy of activation and decrease the surface area available for corrosion. From Table 2 it is seen that the value of activation energy $(E)$ for the corrosion of the alloy in the $\mathrm{HCl}$ acid solution in the presence of the inhibitor is higher than that in the absence of the inhibitor. Also, the extent of increase is proportional to the inhibitor concentration, indicating that the energy barrier for the corrosion reaction increases with the increase in the concentration of inhibitor. The increase in the activation energy E may be considered to be due to the physical adsorption of the inhibitor, which results in the increase in surface coverage with the increase in the concentration of the inhibitor. The values at different temperatures also reveal that the inhibition efficiency decreases with the increase in temperature. This may be due to the decrease in the adsorption of the inhibitor on the alloy surface as the temperature increases and a corresponding increase in the corrosion rate due to the greater area of metal being exposed to the acid [19]. Also, activation energy decreased as acid motion increased, this may be attributed to the removal of inhibitor layer from metal surface which facilities the corrosion reaction. It is known from Eq. 4 that the higher activation values lead to the lower corrosion rate. This is due to the formation of a film on the metal surface serving as an energy barrier for the metal corrosion [18, 20]. Zarrouk et al [21] studied the corrosion of copper in acidic media. They showed that corrosion rate increased with increasing temperature both in uninhibited and inhibited solutions while the inhibition efficiency of inhibitor decreased with temperature. A decrease in inhibition efficiencies with the increase temperature in presence of inhibitor might be due to weakening of physical adsorption.

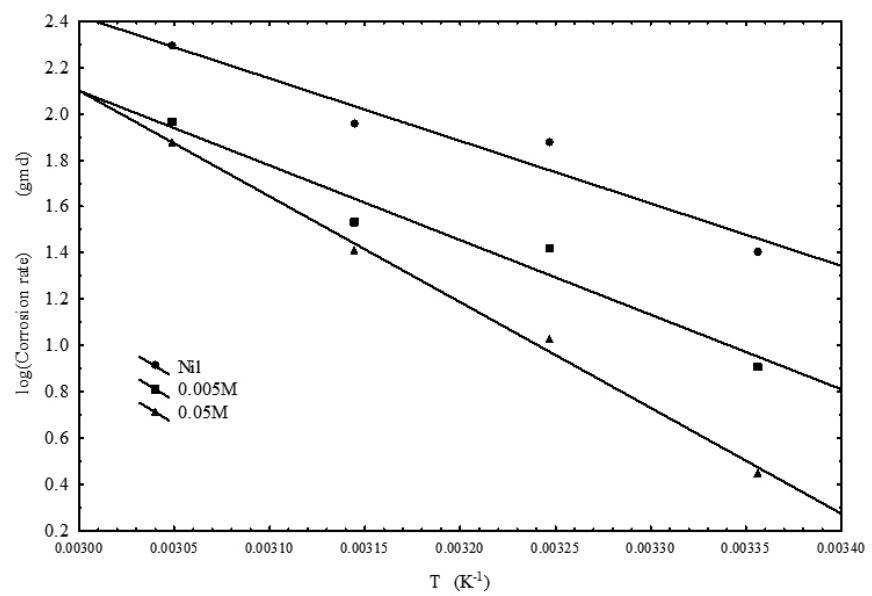

Fig. 1 Arrhenius plot at 100 rpm.

\subsection{Effect of inhibitor concentration}

The adsorption of inhibitor at metal/solution interfaces can markedly change the corrosion resisting properties of metals. The efficiency of organic molecules as good corrosion inhibitors mainly depends on their adsorption ability on the metal surface. So, the investigation of the relation between corrosion inhibition and adsorption is of great importance. The surface coverage $(\theta=\mathrm{IE} \% / 100)$ data are very useful while discussing the adsorption characteristics. When the fraction of surface covered is determined as a function of the concentration at constant temperature, adsorption isotherm could be evaluated at equilibrium condition [22]. The values of $\theta$ can be used to determine the thermodynamic parameters and the mode of the adsorption process. Flory-Huggins adsorption isotherm [23] can be applied to test the mechanism of adsorption process

Table 1 Effect of rotation rate, inhibitor concentration and temperature on the corrosion of $\mathrm{Cu}-\mathrm{Ni}$ in $5 \% \mathrm{HCl}$ solution in absence and presence

\begin{tabular}{|c|c|c|c|c|c|}
\hline No & $\mathrm{C}(\mathrm{M})$ & $\mathrm{T}\left({ }^{\circ} \mathrm{C}\right)$ & $\mathrm{V} \quad(\mathrm{rpm})$ & $\mathrm{C}_{\mathrm{R}}(\mathrm{gmd})$ & $\mathrm{IE} \%$ \\
\hline 1 & \multirow{12}{*}{ Nil } & \multirow{3}{*}{25} & 100 & 25.63 & 0 \\
\hline 2 & & & 200 & 68.79 & 0 \\
\hline 3 & & & 300 & 80.11 & 0 \\
\hline 4 & & \multirow{3}{*}{35} & 100 & 75.503 & 0 \\
\hline 5 & & & 200 & 93.61 & 0 \\
\hline 6 & & & 300 & 98.23 & 0 \\
\hline 7 & & \multirow{3}{*}{45} & 100 & 90.98 & 0 \\
\hline 8 & & & 200 & 188.73 & 0 \\
\hline 9 & & & 300 & 222.35 & 0 \\
\hline 10 & & \multirow{3}{*}{55} & 100 & 199.54 & 0 \\
\hline 11 & & & 200 & 250.11 & 0 \\
\hline 12 & & & 300 & 310.91 & 0 \\
\hline 13 & \multirow{12}{*}{0.005} & \multirow{3}{*}{25} & 100 & 8.12 & 68.3 \\
\hline 14 & & & 200 & 25.59 & 62.79 \\
\hline 15 & & & 300 & 33.91 & 57.67 \\
\hline 16 & & \multirow{3}{*}{35} & 100 & 26.42 & 65.1 \\
\hline 17 & & & 200 & 38.84 & 58.5 \\
\hline 18 & & & 300 & 48.42 & 50.7 \\
\hline 19 & & \multirow{3}{*}{45} & 100 & 34.21 & 62.4 \\
\hline 20 & & & 200 & 93.04 & 50.7 \\
\hline 21 & & & 300 & 132.74 & 40.3 \\
\hline 22 & & \multirow{3}{*}{55} & 100 & 93.18 & 53.3 \\
\hline 23 & & & 200 & 146.06 & 41.6 \\
\hline 24 & & & 300 & 209.86 & 32.5 \\
\hline 25 & \multirow{12}{*}{0.05} & \multirow{3}{*}{25} & 100 & 2.85 & 88.87 \\
\hline 26 & & & 200 & 16.29 & 76.32 \\
\hline 27 & & & 300 & 24.38 & 69.56 \\
\hline 28 & & \multirow{3}{*}{35} & 100 & 10.72 & 85.8 \\
\hline 29 & & & 200 & 27.89 & 70.2 \\
\hline 30 & & & 300 & 38.21 & 61.1 \\
\hline 31 & & \multirow{3}{*}{45} & 100 & 25.93 & 71.5 \\
\hline 32 & & & 200 & 83.23 & 55.9 \\
\hline 33 & & & 300 & 112.51 & 49.4 \\
\hline 34 & & \multirow{3}{*}{55} & 100 & 75.02 & 62.4 \\
\hline 35 & & & 200 & 113.55 & 54.6 \\
\hline 36 & & & 300 & 177.52 & 42.9 \\
\hline
\end{tabular}
of inhibitor. 


$$
\frac{\theta}{x(1-\theta)^{x}}=K_{a d s} C
$$

This model based on the principle of adsorption of organic inhibitors at the metal/solution interface takes place through the replacement of water molecules by organic inhibitor molecules according to following process [22].

$$
\mathrm{Org}_{\text {sol }}+x \mathrm{H}_{2} \mathrm{O}_{\text {ads }} \leftrightarrow \mathrm{Org}_{\text {ads }}+x \mathrm{H}_{2} \mathrm{O}_{\text {sol }}
$$

where $\operatorname{Org}(\mathrm{sol})$ and $\operatorname{Org}$ (ads) are organic molecules in the solution and adsorbed on the metal surface, respectively. $\mathrm{K}_{\text {ads }}$ is the adsorption constant, $\mathrm{C}$ is inhibitor concentration, and $\mathrm{x}$ is the number of water molecules replaced by the organic molecules. The values of $\mathrm{K}_{\text {ads }}$ are in relation with temperature by the following equation [24]:

$$
K_{\text {ads }}=\frac{1}{55.55} \exp \left(-\frac{Q_{a d s}^{o}}{R T}\right) \quad 7
$$

Where $\left(Q_{a d s}^{o}\right)$, the standard adsorption free energy, 55.55 are the concentration of water in solution expressed in $\mathrm{M}, \mathrm{R}$ is gas constant, and $\mathrm{T}$ absolute temperature. Equation 7 can be combined with equation 5 to yield the following equation:

$$
\frac{\theta}{x(1-\theta)^{x}}=\frac{1}{55.55} \exp \left(-\frac{Q_{a d s}^{o}}{R T}\right) C
$$

Nonlinear estimation regression method was used to evaluate the constants of equation 8. Estimation method was done using STATISTICA software computer program, which produce the following equation with 0.8231 correlation coefficient:

$$
\frac{\theta}{0.91(1-\theta)^{0.91}}=\frac{1}{55.55} \exp \left(-\frac{18.78}{R T}\right) C
$$

The average value of $x$ is near unity $(x=0.91)$, which indicates that inhibitor molecules remove one water molecules from metal surface and the inhibitor forms monolayer on metal surface. The average value of $\mathrm{Q}_{\mathrm{ads}}$ was $-18.78 \mathrm{~kJ} / \mathrm{mol}$. The value of $\mathrm{Q}_{\mathrm{ads}}$ was negative this indicates that the process under study is spontaneous [25]. Generally, value of $Q$ up to $-20 \mathrm{~kJ} \cdot \mathrm{mol}^{-1}$ is consistent with electrostatic interaction between the charged molecules and the charged metal (physisorption) while those around $-40 \mathrm{~kJ} \cdot \mathrm{mol}^{-1}$ or higher than that are associated with chemisorptions as a result of sharing or transferring of electrons from the organic molecules to the metal surface to form a coordinate type of bond [26]. It is well known that decrease in efficiency with the increase of temperature is attributed to the physical adsorption. The time gap between the process of adsorption and desorption of inhibitor molecules over the metal surface is becoming shorter with increase in the temperature. Hence, the metal surface remains exposed to the acid environment for longer period, therefore the inhibition efficiency falls at elevated temperature. The inhibitor efficiency decreased with rotation rate increasing, this may be attributed to the separation of protective layer with rotation rate increasing. Fouda et al [27] studied the corrosion inhibition of $\mathrm{Cu} 10 \mathrm{Ni}$ alloy in acidic environment. They found that the inhibition was increase with increasing inhibitor concentrations and decreases with increasing temperature.

1.3 Effect of rotation rate

The corrosion rates of $\mathrm{Cu}-\mathrm{Ni}$ alloy in $5 \% \mathrm{HCl}$ solution are determined at different velocities, temperatures, and inhibitor concentrations. Table 1 shows that as the rotation rate increased, the corrosion rate also increased at different conditions. The effect of flow on the corrosion rate of copper has been used in a number of instances to determine if corrosion is under activation, diffusion, or mixed control. It was shown that the linear increasing of corrosion rate with rotation rate indicate that the corrosion process under diffusion control, while the slightly increasing indicate the mixed control process, and no effect of rotation rate for activation control process. Figure 2 shows the effect of rotation rate on corrosion rate in absence of inhibitor which reflects the mixed control corrosion process. As temperature increased the effect of speed of rotation on corrosion process increased. The same behavior observed in presence of inhibitors. The increase in fluid flow generally increases metal total weight loss by supplying the corrosives at faster rates. Relative metal/environment motion thins the quiescent layers at the metal leading to less restriction of corrosives by diffusion process. When rotation rate becomes extremely high mechanical effects add to corrosion and increase the damage to metals (i.e. Erosion). Results of Lopes - Sesenes et al [28] showed that for uninhibited conditions, the corrosion rate increases as the rotation speed increased up to $500 \mathrm{rpm}$, and then decreased with a further increase in the rotation speed; for inhibited solution, corrosion rate was lowest under static conditions and it increased with a further increase in the rotation speed.

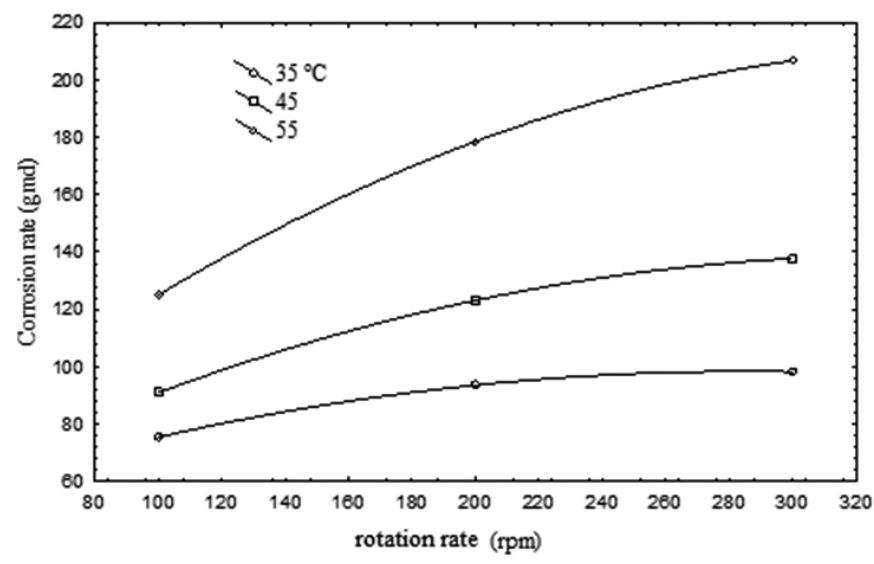

Fig. 2 The effect of rotation rate on the corrosion of Cu-Ni Alloy in 5\% $\mathrm{HCl}$ solution in absence of inhibitor.

\subsection{Mathematical models}

The experimental corrosion rate results in uninhibited and inhibited $5 \%$ $\mathrm{HCl}$ acid as a function of temperature, rotation rate, and inhibitor concentration are given in Table 1. Second order polynomial model and exponential model were used to represent these variables. These models take into account the effect of temperature, inhibitor concentration, rotation rate, and the interaction of them on corrosion rate. The first second order model was:

10

Another second exponential model was also suggested, which based on following assumptions:-

1. The corrosion rate results can be related to temperature by Arrhenius type, which give an indication that the corrosion rate depend exponentially on temperature reciprocal:

$$
C_{R} \propto \exp \left(-\frac{1}{T}\right)
$$

2. The corrosion rate decreases as the inhibitor concentration increased and as acid rotation rate decreased, so;

$$
C_{R} \propto \frac{V^{B_{\Perp}}}{C^{B_{\mathrm{P}}}}
$$

These two assumptions yield to suggest the second exponential model:

$$
C_{R}=B_{10} V^{B_{11}} C^{-B_{12}} \exp \left(-\frac{B_{13}}{T}\right)
$$

Where CR, T, C and V are corrosion rate $\left(\mathrm{g} \cdot \mathrm{m}^{-2} \cdot \mathrm{h}^{-1}\right)$, temperature $(\mathrm{K})$, inhibitor concentration $(\mathrm{M})$ and rotation rate $(\mathrm{rpm})$ respectively. Nonlinear least squares regression analysis based on Levenberg-Marquardt estimation method can be used for estimation of coefficients $\mathrm{B}_{0}, \mathrm{~B}_{1}, \ldots \mathrm{B}_{11}$, producing the 
following equation for $\mathrm{Cu}-\mathrm{Ni}$ alloy with 0.9882 correlation coefficient for first model (eq. 10):

$C R=2956-23.6 T+0.044 T^{2}-48.8 T C-17805 C+306479 C^{2}-7.1 V-0.000 \sigma^{2}-1.5 V C-0.022 V T$

And another estimated model (eq.11) with 0.9767 correlation coefficients:

$$
C_{R}=6.7 \times 10^{7} V^{0.6} C^{-0.04} \exp \left(-\frac{5399}{T}\right)
$$

Generally, correlation coefficient up to 0.30 indicates a weak relationship and is of uncertain validity; between 0.50 and 0.70 indicates a significant relationship and is of practical importance; while above 0.90 means a strong relationship [29]. Fig. 3 shows predicted corrosion rate by equations 10 and 11 against experimental one. This figure shows that the both models represent the corrosion rate data with high correlation coefficients. Furthermore, the constant $\mathrm{B}_{13}$ in equation 11 can be compared with temperature coefficient in Arrhenius equation (eq. 3), this mean that ${ }_{B_{\mathrm{B}}}=\frac{-E}{R}=-5399$, which activation energy value

$\mathrm{E}=44.88 \mathrm{~kJ} \cdot \mathrm{mole}^{-1}$. This value within the range of activation energy listed in Table 2.

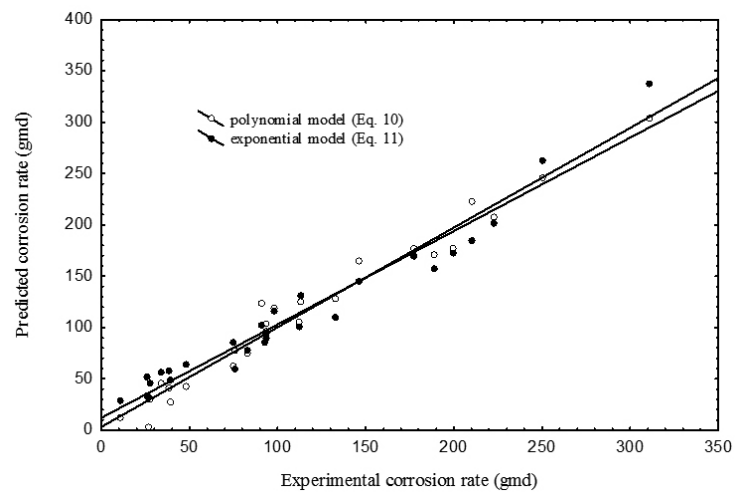
one.

Fig. 3 Predicted corrosion rate by equations 10 and 11 against experimental

Table 2 Arrhenius parameters at different conditions.

\begin{tabular}{|c|c|c|}
\hline Inhibitor conc. M & rotation rate (rpm) & Activation energy $(\mathrm{kJ} / \mathrm{mol})$ \\
\hline 0 & \multirow{3}{*}{100} & 40.98 \\
\hline 0.005 & & 53.16 \\
\hline 0.050 & & 82.50 \\
\hline 0 & \multirow{3}{*}{200} & 36.79 \\
\hline 0.005 & & 44.75 \\
\hline 0.050 & & 74.42 \\
\hline 0 & \multirow{3}{*}{300} & 30.61 \\
\hline 0.005 & & 41.88 \\
\hline 0.050 & & 67.17 \\
\hline
\end{tabular}

CONCLUSION

The corrosion of $\mathrm{Cu}-\mathrm{Ni}$ alloy in $5 \% \mathrm{HCl}$ was increased with both temperature and acid motion, and decreased with inhibitor concentration. The protection effect of inhibitor was due to formation of physical monolayer on metal surface. The corrosion reaction was controlled by both hydrogen evolution reaction and oxygen reduction. Mathematical modeling was used to fitting the corrosion rate data. The both suggested polynomial and exponential models represent the data successfully with correlation coefficients.

\section{ACKNOWLEDGEMENT}

This work was supported by Baghdad University, Chemical
Engineering Department, which is gratefully acknowledged. Also, special thanks to Prof. Dr. Aprael S. Yaro for his continuous support.

\section{REFERENCES}

[1]. S. A. Umoren, I. B. Obot, I. O. Igwe, Op. Corro. J.2 (2009)1-7.

[2]. A. Y. Musa, A. A. H. Kadhum, A. B. Mohamad, M. S. Takriff, A. R. Daud, S. K. KamarudinCorros. Sci. 52(2010) 526-533.

[3]. A. Y. Musa, A. A. H. Kadhum, A. B. Mohamad, A. A. B. Rahoma, H. Mesmari, J. Mole. Struc. 969 (2010) 233-237.

[4]. A. Y. Musa, A. A. Khadom, Abdul Amir H. Kadhum, Kinetic Approach To Mild Steel Corrosion Inhibition by 4-amino-5-phenyl-4H-1, 2, 4-triazole3-thiol, Journal of the Taiwan Institute of Chemical Engineers, 41 (2010) 126-128.

[5]. A. A. Khadom, Molecular Structure of Phenylthiourea as a Corrosion Inhibitor of Mild Steel in Hydrochloric Acid, Corrosion Science and Protection Technology, Vol. 32, No.6, pp. 457 - 462, 2011.

[6]. A. A. Khadom , A. Y. Musa , Abdul Amir H. Kadhum, Abu Bakar Mohamad, Mohd Sobri Takriff, Adsorption Kinetics of 4-Amino-5Phenyl-4H-1, 2, 4-Triazole-3-thiol on Mild Steel Surface Inhibitor, Portugaliae Electrochimica Acta, 28, (2010) 221 - 230.

[7]. Bentiss, F. Traisnel, M. Gengembre, L. Lagrenée, M. Inhibition of acidic corrosion of mild steel by 3,5-diphenyl-4H-1,2,4-triazole, Applied Surface Science, 161, pp. 194-202, 2000.

[8]. Khaled, K.F., Adsorption and inhibitive properties of a new synthesized guanidine derivative on corrosion of copper in $0.5 \mathrm{M} \mathrm{H}_{2} \mathrm{SO}_{4}$, Applied Surface Science, 255, pp.1811-1818, 2008.

[9]. A. A. Khadom, A. S. Yaro and A. A. H. Kadhum: 'Adsorption mechanism of benzotriazole for corrosion inhibition of coppernickel alloy in hydrochloric acid', J. Chil. Chem. Soc., 2010, 55,150-152.

[10]. A. Y. Musa, A. A. Khadom, A. A. H. Kadhum, A. B. Mohamad and M. S. Takriff: 'The role of 4-amino-5-phenyl-4H-1, 2, 4- trizole-3-thiol on the inhibition of nickel-aluminum bronze alloy corrosion: electrochemical and quantum chemical studies', Res. Chem. Intermed., 2012, 38, 91-103.

[11]. Yaro A. S., Khadom A. A., Ibraheem H. F., Peach juice as an anti-corrosion inhibitor of mild steel, Anti - Corrosion Methods and Materials, 58 (3), pp. $116-124,2011$.

[12]. Poornima, T. Jagannath Nayak, A. Nityananda Shetty, Effect of 4-(N,Ndiethylamino)benzaldehyde thiosemicarbazone on the corrosion of aged $18 \mathrm{Ni} 250$ grade maraging steel in phosphoric acid solution, Corrosion Science, 53, pp. 3688-3696, 2011.

[13]. Khadom, A. A., Yaro,A. S., AlTaie, A. S. Kadum, A. A. H., Electrochemical, Activations and Adsorption Studies for the Corrosion Inhibition of Low Carbon Steel in Acidic Media, Portugaliae Electrochimica Acta, 27(6), pp. 699-712, 2009.

[14]. Wei-hua Li, Qiao He, Sheng-tao Zhang, Chang-ling Pei, Bao-rong Hou, Some new triazole derivatives as inhibitors for mild steel corrosion in acidic medium, Journal of Applied Electrochemistry, 38, pp. 289-295, 2008.

[15]. Khadom A. A., Aprael S. Yaro, Ahmed Y. Musa, Abu Bakar Mohamad, and Abdul Amir H. Kadhum, Corrosion Inhibition of Copper-nickel Alloy: Experimental and Theoretical Studies, Journal of the Korean Chemical Society, 56 (4), pp. 406 - 415, 2012.

[16]. Khadom, A. A. and Yaro, A. S. Modeling of Corrosion Inhibition of Copper-Nickel Alloy in Hydrochloric Acid by Benzotriazole, Russian Journal of Physical Chemistry A, 85 (11), pp. 2005-2012, 2011.

[17]. I.B. Obot, S. AUmoren, N.O. Obi-Egbedi, J. Mater. Environ. Sci. 2 (2011) 60-71.

[18]. Khadom, A. A., Yaro, A. S., Abdul Amir H.K., Ahmed S. AlTaie, Ahmed Y. Musa, The Effect of Temperature and Acid Concentration on Corrosion of Low Carbon Steel in Hydrochloric Acid Media, American Journal of Applied Sciences, 6 (9), pp. 1403-1409, 2009.

[19]. Da-Quan Zhang, Qi-Rui Cai, Li-Xin Gao, Kang Yong Lee, Effect of serine, threonine and glutamic acid on the corrosion of copper in aerated hydrochloric acid solution, Corrosion Science, 50 (1), pp. 3615-3621, 2008.

[20]. Fouda A.S.; A.A. Al-Sarawy, E.E. El-Katori, (2006): Pyrazolone derivatives as corrosion inhibitors for Mild steel $\mathrm{HCl}$ solution, Desalination, 201,1-13.

[21]. Zarrouk , B. Hammouti, H. Zarrok, M. Bouachrine, K.F. Khaled, S.S. Al-Deyab, Corrosion Inhibition of Copper in Nitric Acid Solutions Using a New Triazole Derivative, Int. J. Electrochem. Sci., 7 (2012) 89 - 105.

[22]. El-Sayed M. Sherif, R.M. Erasmus, J.D. Comins, Inhibition of copper 
corrosion in acidic chloride pickling solutions by 5 -(3-aminophenyl)tetrazole as a corrosion inhibitor, Corrosion Science, 50 (1), pp. 3439$3445,2008$.

[23]. L. Larabi, O. Benali, S.M. Mekelleche, Y. Harek, 2-Mercapto-1methylimidazole as corrosion inhibitor for copper in hydrochloric acid, Applied Surface Science, 253, pp.1371-1378, 2006.

[24]. H.L. Wang, R.B. Liu, J. Xin, Inhibiting effects of some mercapto triazole derivatives on the corrosion of mild steel in $10 \mathrm{M} \mathrm{HCl}$ medium, Corros. Sci. 46 (2004) 2455-2466.

[25]. K.C. Emregul, R. Kurtaran, O. Atakol, An investigation of chloridesubstituted Schiff bases as corrosion inhibitors for steel, Corros. Sci. 45 (2003) 2803-2817.
[26]. Lalitha, A., Ramesh, S., Rajeswari, S., Surface protection of copper in acid medium by azoles and surfactants, Electrochimica Acta 51, pp.47$55,2005$.

[27]. A. S. Fouda, M. Abdallah, M. El-Hoseiny, Acrylonitrile derivatives as corrosion inhibitors for $\mathrm{Cu} 10 \mathrm{Ni}$ alloy in $0.5 \mathrm{M}$ hydrochloric acid solution, African Journal of Pure and Applied Chemistry, 7, 252-263, 2013.

[28]. R. Lopes-Sesenes, G.F. Dominguez-Patiño, J.G. Gonzalez-Rodriguez, J. Uruchurtu-Chavarin, Effect of Flowing Conditions on the Corrosion Inhibition of Carbon Steel by Extract of Buddleia Perfoliata, Int. J. Electrochem. Sci., 8 (2013) 477 - 489.

[29]. Lazic', Z. R., Design of Experiments in Chemical Engineering, Wiley VCH Verlag GmbH \& Co. KGaA, Weinheim, 2004. 